\title{
MATRIK
}

Jurnal Manajemen dan Teknik Industri-Produksi

Journal homepage: http://www.journal.umg.ac.id/index.php/matriks

\section{Penentuan Mitigasi Risiko pada Rantai Pasok IKM Manufaktur}

\section{Tigar Putri Adhiana ${ }^{1 *}$, Ayu Anggraeni Sibarani ${ }^{2 *}$}

Program Studi Teknik Industri, Fakultas Teknik, Universitas Jenderal Soedirman Jl. Mayjen Sungkono KM. 5 Blater, Kalimanah, Purbalingga, Jawa Tengah, Indonesia tigar.adhiana@unsoed.ac.id, ayu.anggraeni.sibarani@unsoed.ac.id

\section{INFO ARTIKEL}

doi: $10.350587 /$ Matrik v18i2.589

\section{Jejak Artikel : \\ Upload artikel \\ 29 Januari 2020 \\ Revisi oleh reviewer \\ 10 Oktober 2020 \\ Publish \\ 16 September 2020}

\section{Kata Kunci :}

risiko; rantai pasok, risiko rantai pasok, industry kecil menengah

\section{ABSTRAK}

Risiko dalam rantai pasok muncul sebagai peristiwa apa pun yang dapat memengaruhi gerakan aliran material mulai dari pemasok sampai konsumen dan mengganggu aliran material yang direncanakan. Maka dari itu untuk menunjang kelancaran proses produksi perlu dilakukan identifikasi risiko kemudian selanjutnya dilakukan mitigasi risiko. Penelitian ini dilakukan di IKM X yang merupakan salah satu IKM produksi knalpot terbesar di Kabupaten Purbalingga. Dari hasil observasi awal diperoleh bahwa tidak ada standar dalam proses produksi knalpot dan IKM X tidak memiliki safety stock, sehingga IKM sering mengalami lost sales. Tujuan dari penelitian ini adalah untuk mengidentifikasi risiko yang ada pada IKM X dan merumuskan strategi mitigasi risiko. IKM sebagai usaha yang ukuran bisnisnya tidak terlalu besar sangat rentan terkena risiko pada rantai pasoknya. Metode yang digunakan dalam penelitian ini adalah metode House of Risk (HOR). Langkah awal adalah melakukan pemeetaan rantai pasok pada IKM X. Selanjutnya melakukan identifikasi risk agent dan risk event identifikasi risiko. Langkah berikutnya adalah analisis risiko menggunakan metode House of Risk (HOR). Langkah terakhir adalah merumuskan rancangan mitigasi risiko. Dari hasil pengolahan data diperoleh 27 risk event dan 17 risk agent. Sedangkan dalam perumusan strategi mitigasi diperoleh 10 rancangan mitigasi risiko. 


\section{Pendahuluan}

Agar konsumen dapat memperoleh produknya pada waktu dan jumlah yang tepat maka perlu koordinasi yang baik antar tiap entitas di rantai pasok. Menurut [7], rantai pasok adalah perusahaan-perusahaan yang secara bersama-sama bekerja untuk menciptakan dan mengantarkan suatu produk ke tangan konsumen.

Dalam pelaksanaan pemenuhan kebutuhannya kepada konsumen, tentunya terdapat beberapa risiko yang mungkin terjadi dalam sebuah rantai pasok. Risiko dapat didefinisikan secara luas sebagai peluang bahaya, kerusakan, kehilangan, cedera, atau konsekuensi lain yang tidak diinginkan. Risiko juga adalah probabilitas bahwa peristiwa buruk terjadi selama periode waktu, atau hasil dari tantangan tertentu [5]. Risiko dalam rantai pasok muncul sebagai peristiwa apa pun yang dapat mempengaruhi gerakan aliran material mulai dari pemasok sampai konsumen dan mengganggu aliran material yang direncanakan. Pada sebuah rantai pasokan semua anggota saling terkait, dan apabila ada risiko terhadap satu entitas, secara otomatis ditransfer ke semua anggota lainnya [11]. Dampak dari terjadinya risiko adalah kerugian baik dari sisi kehilangan pendapatan maupun pencitraan perusahaan atau produk yang menurun [4].

Kabupaten Purbalingga memiliki berbagai IKM yang dikelola oleh masyarakat. Salah satu IKM yang paling terkenal di Purbalingga adalah IKM produsen Knalpot. Pertumbuhan jumlah IKM Knalpot semakin bertambah setiap tahunnya. Menurut Dinas Perindagkop \& IKM, pada tahun 2017 terdapat 49 jumlah produsen knalpot. Selain itu, knalpot buatan Kabupaten Purbalingga sudah dikenal dan diakui oleh produsen otomotif. Jenis knalpot yang diproduksi di Kabupaten Purbalingga antara lain adalah knalpot motor dan knalpot mobil. Sehingga dapat disimpulkan bahwa industri knalpot merupakan salah satu industri yang memiliki potensi untuk dikembangkan.

Dari penjelasan diatas dapat dilihat bahwa IKM Knalpot dituntut untuk kompetitif sehingga tak hanya dapat memenuhi kebutuhan konsumennya tapi juga dapat memperoleh keuntungan penjualan. Maka dari itu untuk menunjang kelancaran proses produksi di IKM Knalpot perlu dilakukan identifikasi risiko yang berpotensi muncul kemudian selanjutnya dilakukan mitigasi risiko dari hasil identifikasi risiko yang telah diperoleh sebelumnya. Sehingga dapat dilakukan pengelolaan terhadap risiko-risiko rantai pasok yang kemungkinan akan muncul pada saat produksi.

IKM $X$ adalah salah satu IKM produksi knalpot terbesar di Kabupaten Purbalingga. Produk knalpot yang diproduksi adalah knalpot untuk motor 2 tak dan knalpot motor 4 tak. Tetapi yang diproduksi secara konstan mayoritas adalah knalpot 4 tak. Jumlah produksi kenalpot per hari mencapai 60 knalpot. Dari hasil observasi awal diperoleh bahwa tidak ada standar dalam proses produksi knalpot dan tidak memiliki safety stock. Sehingga IKM sering mengalami lost sales.

Berbagai penelitian tentang manajemen risiko rantai pasok telah dilakukan, diantaranya dengan metode logika fuzzy untuk mengidentifikasi dan evaluasi risiko rantai pasok komoditas jagung [10]. Penelitian [2] mengidentifikasi dan merumuskan strategi mitigasi risiko pada saat pengembangan produk baru yaitu produk hijab. Metode yang digunakan adalah Failure Mode Effect and Critically Analysis (FMECA) and House Of Risk (HOR). [9] melakukan penelitian untuk mengidentifikasi risiko pada restoran yang menyediakan makanan halal menggunakan metode FMEA atau Failure Mode and Effect Analysis. [3] melakukan analisa dan evaluasi risiko yang berpotensi timbul pada suatu rantai pasok menggunakan metode FMEA. Penelitian [6] melakukan identifikasi dan mitigasi risiko pada bahan baku kulit untuk perusahaan sepatu. Metode yang digunakan adalah metode House of Risk (HOR). Sedangkan studi oleh [1], yaitu melakukan analisis tentang risiko kualitas pada rantai pasok udang beku.

Berbeda dengan penelitian sebelumnya, penelitian ini mengidentifikasi dan merumuskan mitigasi atau pengelolaan risiko dilakukan pada IKM. IKM sebagai usaha yang ukuran bisnisnya tidak terlalu besar sangat rentan terkena risiko pada rantai pasoknya. Identifikasi risiko perlu dilakukan sehingga IKM dapat melakukan prediksi risiko dan hambatan pada proses. Penelitian ini bertujuan 
untuk menganalisis risiko dan merumuskan mitigasi risiko pada IKM.

Pada penelitian ini, pengumpulan data menggunakan wawancara, brainstorming, pengisian kuesioner dengan pemilik IKM X dan pekerja IKM X serta observasi lapangan. Langkah pertama adalah wawancara dan observasi untuk memetakan rantai pasok IKM. Selanjutnya adalah identifikasi risiko yang terdiri dari risk agent dan risk event. Identifikasi risk agent dan risk event dilakukan dengan wawancara dengan pihak IKM. Identifikasi risiko menggunakan klasifikasi dari [8] seperti yang tercantum pada Gambar 1 .

Langkah selanjunya setelah identifikasi risiko adalah analisis risiko. Metode yang digunakan adalah metode House of Risk (HOR). Metode HOR merupakan sebuah metode yang dikembangkan oleh [3]. Metode HOR 1 melakukan analisis risiko yang diprioritaskan untuk dirumuskan tindakan pencegahannya. Prioritas risiko ditentukan dengan nilai ARP dan diagram pareto. Perhitungan nilai ARP ditentukan oleh nilai occurrence, severity, dan hubungan kejadian. Skala pengukuran yang digunakan adalah skala likert 1, 3, 5, 7, 9. Perhitungan ARP adalah :

$A R P_{j}=O_{j} \Sigma S_{i} R_{i j}$

Dimana :

$A R P_{j}=$ aggregate risk potential

$O_{j}=$ kemungkinan kejadian (occurrence)

$S_{i}=$ dampak risiko (severity)

$R_{i j}=$ hubungan antara occurence dan severity

Setelah menyusun prioritas nilai ARP dibuat diagram pareto dari ARP untuk semua risiko. Selanjutnya adalah pengolahan data menggunakan HOR 2. Tahap HOR 2 bertujuan

\section{Metode Penelitian}

untuk menenetukan prioritas tindakan mitigasi risiko.

Pada tahap HOR 2 ini dilakukan perhitungan total efektivitas dari tiap tindakan mitigasi. Penilaian tingkat efektivitas dilakukan oleh pemilik IKM. Penentuan nilai efektivitas menggunakan skala likert 1, 3, 5, 7, 9. Persamaannya sebagai berikut.

$T E_{k}=A R P_{j} E j_{k} \quad \forall k j$

$T E_{k}=$ total efektivitas

$\mathrm{A} R P_{j}=$ aggregate risk potential

$E_{j k}=$ nilai efektivitas

Selanjutnya adalah menghitung rasio nilai total efektivitas tindakan mitigasi dengan tingkat kesulitan tindakan mitigasi. Penentuan nilai tingkat kesulitan menggunakan skala likert 1, 3, 5, 7, 9 dengan persamaan sebagai berikut :

$E T D_{k}=T E_{k} / D_{k}$

Dimana :

$E T D_{k}=$ rasio nilai total efektivitas

$T E_{k}=$ total efektivitas

$D_{k}=$ tingkat kesulitan pelaksanaan tindakan mitigasi.

\section{Hasil dan Pembahasan}

\subsection{Pemetaan Rantai Pasok IKM X}

Pemetaan rantai pasok IKM $\mathrm{X}$ diperoleh melalui observasi dan hasil wawancara dengan pemilik IKM X. Hasil pemetaan rantai pasok IKM X dapat dilihat pada Gambar 2.

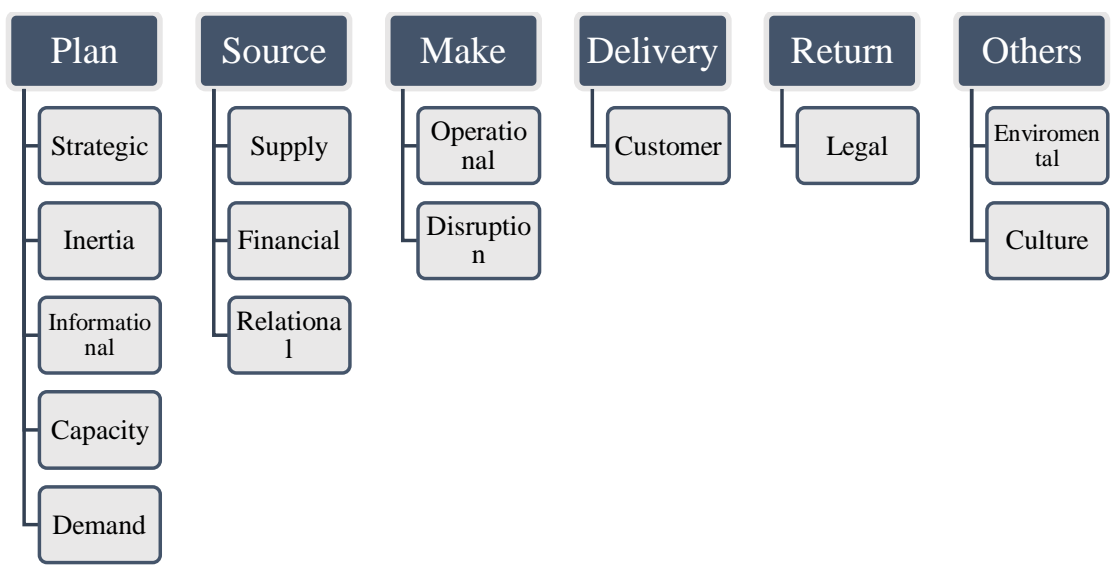

Gambar 1. Klasifikasi Risiko [8] 


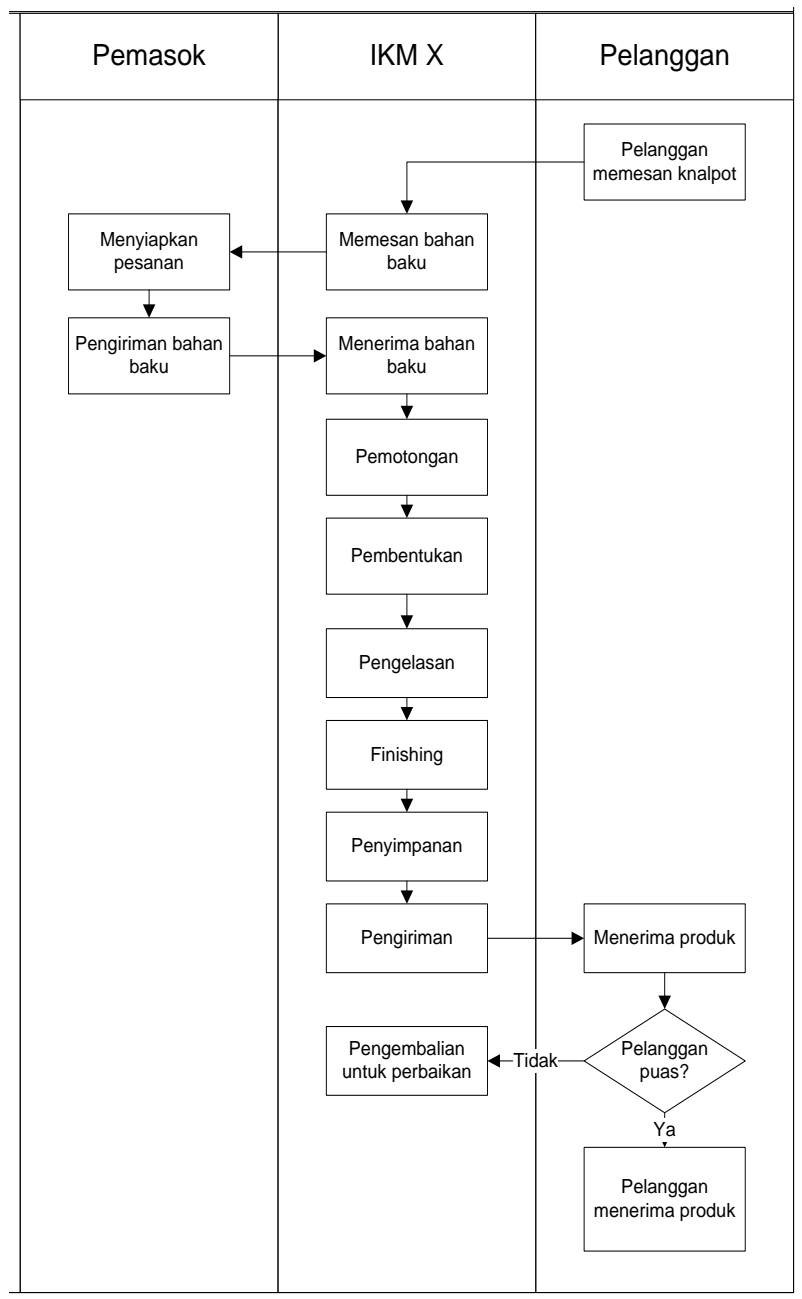

Gambar 2. Rantai Pasok IKM X

Dari Gambar 2 dapat dilihat bahwa rantai pasok dalam IKM $\mathrm{X}$ terdiri dari pemesanan bahan baku ke supplier, proses produksi yang terdiri dari pemotongan, pembentukan, pengelasan, dan finishing. Setelah proses produksi selesai, maka knalpot disimpan dahulu sebelum dilakukan pengiriman.

\subsection{Identifikasi Risk Event dan Risk Agent}

Risk agent (Ai) yang diukur dengan skala occurrence adalah faktor yang menimbulkan kejadian risiko. Sedangkan skala occurrence adalah kemungkinan risiko dapat terjadi sehingga menghambat proses pada rantai pasok. Hasil identifikasi risk agent ditunjukkan pada Tabel 1.
Dari identifikasi risk agent dan risk event, diperoleh 27 risk agent dalam rantai pasokan IKM X. Risk agent tersebut terdiri dari 7 risk agent pada kategori plan. 7 risk agent tersebut terdiri dari risiko yang terjadi pada demand, inertia, capacity, dan informational. 5 risk agent pada kategori source. 5 risk agent tersebut terdiri dari risiko yang terjadi pada financial, supply, dan relational. 9 risk agent pada kategori make. 9 risk agent tersebut terdiri dari risiko yang terjadi pada operational dan disruption. 2 risk agent dalam kategori delivery. 2 risk agent tersebut terdiri dari risiko pada customer. 2 risk agent pada kategori legal 2 risk agent tersebut terdiri dari risiko pada legal. 2 risk agent pada kategori proses lain, yaitu pada environment dan culture. 
Tabel 1. Risk Agent

\begin{tabular}{|c|c|c|c|}
\hline Proses & Risiko & Kode & Risk Agent \\
\hline \multirow{7}{*}{ Plan } & \multirow{2}{*}{ Demand } & A1 & $\begin{array}{l}\text { Jumlah permintaan konsumen yang tidak } \\
\text { pasti }\end{array}$ \\
\hline & & $\mathrm{A} 2$ & $\begin{array}{l}\text { Spesifikasi produk dari konsumen berbeda- } \\
\text { beda }\end{array}$ \\
\hline & Inertia & A3 & Desain yang tidak up to date \\
\hline & \multirow{3}{*}{ Capacity } & A4 & Tidak memiliki safety stock \\
\hline & & A5 & Tidak ada area untuk gudang barang jadi \\
\hline & & A6 & $\begin{array}{l}\text { Area yang terbatas untuk persediaan bahan } \\
\text { baku dan WIP }\end{array}$ \\
\hline & Informational & A7 & Tidak menggunakan sistem informasi \\
\hline \multirow{5}{*}{ Source } & \multirow{2}{*}{ Financial } & A8 & Kenaikan harga bahan baku \\
\hline & & A9 & Pengelolaan keuangan yang masih manual \\
\hline & \multirow{2}{*}{ Supply } & A10 & Hanya memiliki satu pemasok \\
\hline & & A11 & Jarak antara IKM dan supplier jauh \\
\hline & Relational & A12 & Kurangnya koordinasi dengan supplier \\
\hline \multirow{9}{*}{ Make } & \multirow{7}{*}{ Operational } & A13 & Tidak ada standar dalam sistem produksi \\
\hline & & A14 & Mesin mengalami kerusakan \\
\hline & & A15 & Workstations tidak teratur \\
\hline & & A16 & Area produksi yang tidak higienis \\
\hline & & A17 & Kesalahan pada proses produksi \\
\hline & & A18 & Human error pada proses produksi \\
\hline & & A19 & Tidak ada training untuk pekerja baru \\
\hline & \multirow{2}{*}{ Disruption } & A20 & Pekerja yang sering tidak masuk \\
\hline & & A21 & Turnover pekerja tinggi \\
\hline \multirow[b]{2}{*}{ Delivery } & \multirow[b]{2}{*}{ Customer } & A22 & Pengiriman produk ke konsumen lama \\
\hline & & A23 & Armada pengiriman jumlahnya terbatas \\
\hline \multirow{2}{*}{ Return } & \multirow{2}{*}{ Legal } & $\mathrm{A} 24$ & Produk tidak berfungsi \\
\hline & & A25 & Produk defect \\
\hline \multirow{2}{*}{ Other } & Environment & A26 & Ketergantungan pada listrik dari pemerintah \\
\hline & Culture & A27 & Usaha keluarga turun temurun \\
\hline
\end{tabular}

Risk event (Ei) adalah kejadian yang dapat terjadi pada sebuah proses rantai pasok sehingga menyebabkan kerugian. Risk event diukur dengan skala severity. Severity adalah dampak dari sebuah risiko apabila risiko tersebut terjadi. Penilaian severity dari risk event ini menggunakan skala likert 1, 3, 5, 7, 9 . Hasil risk event ditunjukkan pada Tabel 2. Dari tabel 2 dapat diketahui bahwa terdapat 17 risk event pada IKM X. 
Tabel 2. Risk Event

\begin{tabular}{|c|c|l|}
\hline No & Kode & \multicolumn{1}{|c|}{ Risk Event } \\
\hline 1 & E1 & Kesalahan perhitungan perencanaan material \\
\hline 2 & E2 & Proses produksi yang semakin lama/delay \\
\hline 3 & E3 & Pekerja lembur \\
\hline 4 & E4 & Adanya persaingan dengan IKM Knalpot lain \\
\hline 5 & E5 & Kehilangan penjualan \\
\hline 6 & E6 & $\begin{array}{l}\text { Produk jadi disimpan jauh dari lokasi produksi, di } \\
\text { rumah pemilik IKM }\end{array}$ \\
\hline 7 & E7 & Material tercampur di area produksi \\
\hline 8 & E8 & Data rusak atau hilang \\
\hline 9 & E9 & Harga bahan baku mahal \\
\hline 10 & E10 & Kualitas produk rendah \\
\hline 11 & E11 & Terjadinya proses perbaikan pada saat produksi \\
\hline 12 & E12 & Defect pada produk jadi \\
\hline 13 & E13 & $\begin{array}{l}\text { Pelanggan mengembalikan produk untuk diperbaiki } \\
\text { (repair) }\end{array}$ \\
\hline 14 & E14 & Kurangnya jumlah pekerja \\
\hline 15 & E15 & Komplain dari customer \\
\hline 16 & E16 & Harga pengiriman mahal \\
\hline 17 & E17 & Kurangnya profesionalisme \\
\hline
\end{tabular}

\subsection{Pengolahan data dengan Metode House of Risk 1}

Setelah melakukan identifikasi risiko, langkah selanjutnya adalah analisis menggunakan metode HOR 1. HOR 1 melakukan analisis risiko yang diprioritaskan untuk dirumuskan tindakan pencegahannya. Hubungan antara risk agent dan risk event diidentifikasi melalui wawancara dan kuesioner dengan pemilik IKM, dimana pada kuesioner diberi nilai skala likert yaitu 1, 3, 5, 7, 9 sebagai tanda dari masing-masing hubungan antara risk event dan risk agent. Langkah selanjutnya adalah menentukan Aggregate Risk Potentials (ARP) menggunakan persamaan 1. Perhitungan ARP yang diperoleh dapat dilihat pada Tabel 3. Sedangkan dari Gambar 3 dan Tabel 4 dapat diketahui prioritas risk agent yang harus ditangani. Prioritas risiko tersebut adalah tidak ada standar dalam sistem produksi (A13), turnover pekerja tinggi (A21), tidak ada safety stock (A4), pekerja yang sering tidak masuk (A20), tidak ada training untuk pekerja baru (A19), jumlah permintaan konsumen yang tidak pasti (A1), tidak ada area untuk gudang barang jadi (A5), tidak menggunakan sistem informasi (A7).

\subsection{Pengolahan data dengan Metode House of Risk 2}

Tahap selanjutnya adalah menentukan tindakan untuk mitigasi risiko atau tahap pengolahan data dengan HOR 2. Tahap HOR 2 berupa perancangan strategi berdasarkan prioritas tindakan mitigasi. Tabel 5 adalah strategi mitigasi sesuai dengan prioritas risiko. Tindakan mitigasi risiko diperoleh melalui hasil wawancara dan brainstorming dengan pemilik IKM $X$ dan pekerja IKM $X$. 
Tabel 3. Perhitungan HOR 1

\begin{tabular}{|c|c|c|c|c|c|c|c|c|c|c|c|c|c|c|c|c|c|c|c|c|c|c|c|c|c|c|c|c|c|}
\hline & \multicolumn{27}{|c|}{ Risk Agent } & \multirow{2}{*}{ Severity } \\
\hline & & $\mathrm{A} 1$ & $\mathrm{~A} 2$ & A3 & A4 & A5 & $\overline{A 6}$ & A7 & A8 & A9 & $\overline{\mathrm{A} 10}$ & $\bar{A} 11$ & $\mathrm{~A} 12$ & A13 & $\overline{\mathrm{A} 14}$ & A15 & A16 & $\mathrm{A} 1$ & $\mathrm{~A} 18$ & $\mathrm{~A} 1 \mathrm{C}$ & $\overline{\mathrm{A} 2 \mathrm{C}}$ & A21 & A22 & A23 & A24 & A25 & A26 & A27 & \\
\hline \multirow{17}{*}{ 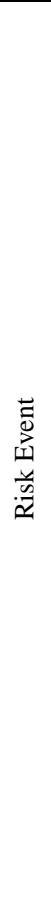 } & E1 & 9 & & & & & & & & & & & & & & & & & & & & & & & & & & & 9 \\
\hline & E2 & & 3 & & & & 3 & & & & & & & & 1 & 3 & & & & & & & & & & & 3 & & 3 \\
\hline & E3 & 7 & 3 & & & & & & & & & & & & 3 & & & & & & & & & & & & & & 5 \\
\hline & $\mathrm{E} 4$ & & & 5 & & & & & & & & & & & & & & & & & & & & & & & & & 5 \\
\hline & E5 & & & & 9 & 5 & & & & & & & & & 5 & & & & & & & & & & & & 3 & & 9 \\
\hline & E6 & & & & & 3 & & & & & & 1 & & & & & & & & & & & & & & & & & 3 \\
\hline & E7 & & & & & & 1 & & & & & & & & & 1 & 1 & & & & & & & & & & & & 1 \\
\hline & E8 & & & & & & & 9 & & 3 & & & & & & & & & & & & & & & & & & & 7 \\
\hline & E9 & & & & & & & & 7 & & 3 & 1 & 5 & & & & & & & & & & & & & & & & 7 \\
\hline & E10 & & & & & & & & & & & & 7 & 7 & & & & 5 & 1 & & & & & & & & & & 7 \\
\hline & E11 & & & & & & & & & & & & & 5 & & & & 3 & & & & & & & & & & & 5 \\
\hline & E12 & & & & & & & & & & & & & 7 & & & & 7 & 5 & & & & & & & & & & 7 \\
\hline & E13 & & & & & & & & & & & & & & & & & & & & & & & & 5 & 5 & & & 5 \\
\hline & E14 & & & & & & & & & & & & & & & & & & & 9 & 7 & 9 & & & & & & & 9 \\
\hline & E15 & & & & & & & & & & & & & & & & & & & & & & 1 & 3 & 5 & 3 & & & 5 \\
\hline & E16 & & & & & & & & & & & & & & & & & & & & & & 3 & 5 & & & & & 5 \\
\hline & E17 & & & & & & & & & & & & & & & & & & & & & & & & & & & 1 & 1 \\
\hline \multicolumn{2}{|c|}{ Occurance } & 9 & 5 & 5 & 9 & 9 & 7 & 7 & 1 & 3 & 3 & 7 & 1 & 7 & 3 & 7 & 7 & 1 & 3 & 7 & 7 & 9 & 5 & 3 & 1 & 3 & 5 & 7 & \\
\hline \multicolumn{2}{|c|}{ ARP } & 1044 & 120 & 125 & 729 & 486 & 70 & 441 & 49 & 63 & 63 & 70 & 84 & 861 & 189 & 70 & 7 & 99 & 126 & 567 & 441 & 729 & 100 & 120 & 50 & 120 & 180 & 7 & \\
\hline & & $15 \%$ & $2 \%$ & $2 \%$ & $10 \%$ & $7 \%$ & $1 \%$ & $6 \%$ & $1 \%$ & $1 \%$ & $1 \%$ & $1 \%$ & $1 \%$ & $12 \%$ & $3 \%$ & $1 \%$ & $0 \%$ & $1 \%$ & $2 \%$ & $8 \%$ & $6 \%$ & $10 \%$ & $1 \%$ & $2 \%$ & $1 \%$ & $2 \%$ & $3 \%$ & $0 \%$ & \\
\hline
\end{tabular}




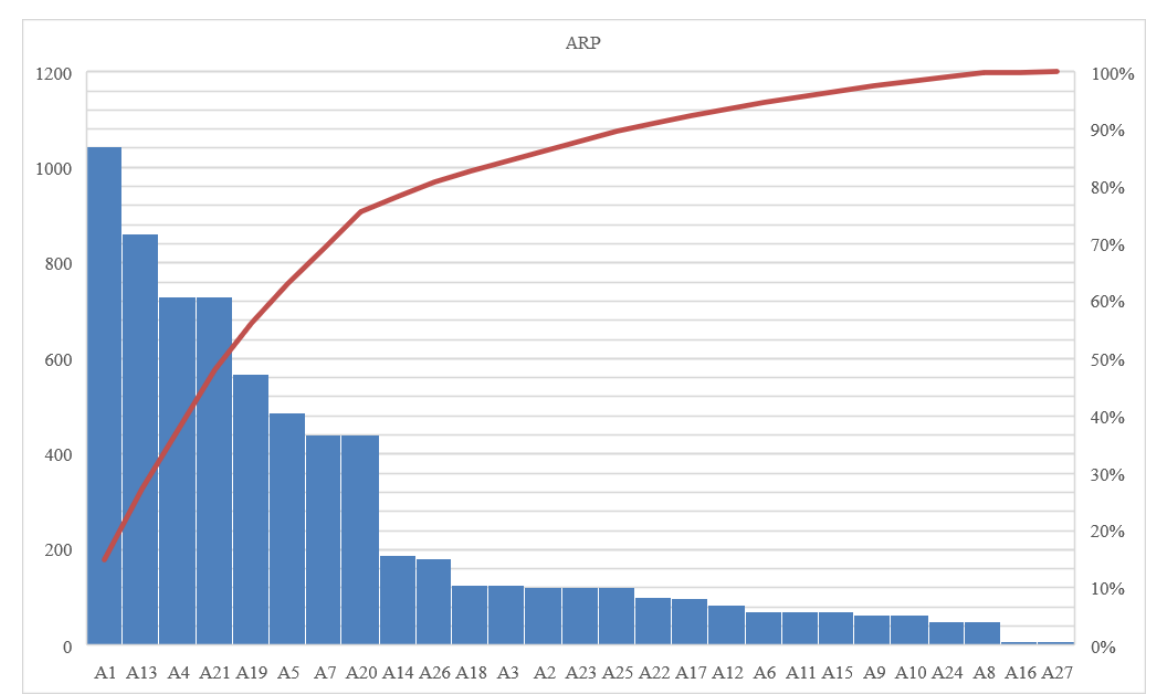

Gambar 3. Diagram Pareto Perhitungan ARP

Tabel 4. Prioritas Risiko

\begin{tabular}{|l|c|}
\hline \multicolumn{1}{|c|}{ Penyebab } & Risiko \\
\hline $\begin{array}{l}\text { Tidak ada standar dalam sistem } \\
\text { produksi }\end{array}$ & $\mathrm{A} 13$ \\
\hline Turnover pekerja tinggi & $\mathrm{A} 21$ \\
\hline Tidak ada safety stock & $\mathrm{A} 4$ \\
\hline Pekerja yang sering tidak masuk & $\mathrm{A} 20$ \\
\hline $\begin{array}{l}\text { Tidak ada training untuk pekerja } \\
\text { baru }\end{array}$ & $\mathrm{A} 19$ \\
\hline $\begin{array}{l}\text { Jumlah permintaan konsumen } \\
\text { yang tidak pasti }\end{array}$ & $\mathrm{A} 1$ \\
\hline $\begin{array}{l}\text { Tidak ada area untuk gudang } \\
\text { barang jadi }\end{array}$ & $\mathrm{A} 5$ \\
\hline $\begin{array}{l}\text { Tidak menggunakan sistem } \\
\text { informasi }\end{array}$ & $\mathrm{A} 7$ \\
\hline
\end{tabular}

Untuk menetapkan tindakan mitigasi yang dipilih maka dilakukan diskusi dengan pemilik IKM. Kemudian pemilik IKM melakukan penilaian tentang tingkat kesulitan melaksanakan tindakan mitigasi. Penilaian kesulitan tindakan mitigasi menggunakan skala likert 1, 3, 5, 7, 9. Selanjutnya dilakukan perhitungan nilai efektifitas mitigasi dengan persamaan 2 dan 3. Hasil perhitungan dapat dilihat pada Tabel 6 .
Tabel 5. Tindakan Mitigasi

\begin{tabular}{|l|l|}
\hline \multicolumn{1}{|c|}{ Tindakan Mitigasi } & Kode \\
\hline Membuat SOP sistem produksi & M1 \\
\hline $\begin{array}{l}\text { Membuat pelatihan untuk pekerja } \\
\text { baru }\end{array}$ & M2 \\
\hline $\begin{array}{l}\text { Membuat panduan standar } \\
\text { perekrutan pekerja baru }\end{array}$ & M3 \\
\hline $\begin{array}{l}\text { Memberikan penghargaan untuk } \\
\text { kinerja pekerja }\end{array}$ & M4 \\
\hline Mengurangi jam lembur & M5 \\
\hline $\begin{array}{l}\text { Membangun komunikasi yang baik } \\
\text { antara IKM dengan pekerja }\end{array}$ & M6 \\
\hline $\begin{array}{l}\text { Membuat gudang persediaan untuk } \\
\text { safety stock }\end{array}$ & M7 \\
\hline Menyediakan safety stock & M8 \\
\hline $\begin{array}{l}\text { Membuat panajemen } \\
\text { pergudangan }\end{array}$ & M9 \\
\hline Melakukan peramalan permintaan & M10 \\
\hline Membangun sistem informasi & M11 \\
\hline $\begin{array}{l}\text { Pelatihan penggunaan sistem } \\
\text { informasi }\end{array}$ & M12 \\
\hline $\begin{array}{l}\text { Melakukan } \\
\text { pemesanan bahan baku }\end{array}$ & M13 \\
\hline
\end{tabular}


Tabel 6. Efektivitas Tindakan Mitigasi

\begin{tabular}{|c|c|c|c|c|c|c|c|c|c|c|c|c|c|c|c|}
\hline & \multicolumn{13}{|c|}{ Risk Agent } & \multirow{2}{*}{ ARP } \\
\hline & & M1 & M2 & M3 & M4 & M5 & M6 & M7 & M8 & M9 & M10 & M11 & M12 & M13 & \\
\hline \multirow{8}{*}{$\begin{array}{l}\overrightarrow{0} \\
D \\
\overrightarrow{0} \\
\vec{y} \\
\vec{a}\end{array}$} & A1 & & & & & & & & & & 9 & & & 5 & 406 \\
\hline & A4 & & & & & & & 5 & 7 & 3 & & & & & 567 \\
\hline & A5 & & & & & & & 9 & & & & & & & 324 \\
\hline & A7 & & & & & & & & & & & 9 & 6 & & 175 \\
\hline & A13 & 9 & & & & & & & & & & & & & 749 \\
\hline & A19 & & 7 & & & & & & & & & & & & 441 \\
\hline & A20 & & & & 5 & & 5 & & & & & & & & 441 \\
\hline & $\mathrm{A} 21$ & & & 3 & & 3 & 5 & & & & & & & & 405 \\
\hline \multicolumn{2}{|r|}{$\mathrm{D}$} & 7 & 5 & 3 & 7 & 5 & 5 & 7 & 5 & 5 & 7 & 9 & 9 & 5 & \\
\hline \multicolumn{2}{|c|}{$\mathrm{TE}$} & 6741 & 3087 & 1215 & 2205 & 1215 & 4230 & 5751 & 3969 & 1701 & 3654 & 1575 & 1050 & 2030 & \\
\hline \multicolumn{2}{|c|}{ ETD } & 963 & 617.4 & 405 & 315 & 243 & 846 & 821.6 & 793.8 & 340.2 & 522 & 175 & 116.7 & 406 & \\
\hline
\end{tabular}

Tindakan mitigasi yang diperoleh dan memiliki nilai rasio yang paling besar, secara berurutan adalah membuat SOP sistem produksi (M1). Meskipun skala produksi suatu IKM tidak terlalu besar, SOP produksi diperlukan karena SOP tersebut merupakan acuan dalam melaksanakan produksi. Sehingga produk knalpot nanti memiliki standar yangs esuai. Mitigasi selanjutnya adala membangun komunikasi yang baik antara IKM dengan pekerja (M6). Hal tersebut dikarenakan berbeda dengan perusahaan yang besar dan memiliki skala produksi yang besar, skala produksi IKM tidak terlalu besar, jumlah pekerja juga tidak sebanyak perusahaan dan cenderung rumahan, maka perlu membangun hubungan yang baik antara pemilik dan pekerja sebagai salah satu bentuk retensi pegawai.

Mitigasi lainnya yaitu membuat gudang persediaan untuk safety stock (M7), menyediakan safety stock (M8), membuat pelatihan untuk pekerja baru (M2), melakukan peramalan permintaan (M10), melakukan penjadwalan pemesanan bahan baku (M13), membuat panduan standar perekrutan pekerja baru (M3), membuat SOP/Manajemen pergudangan (M9), memberikan penghargaan untuk kinerja pekerja (M4), mengurangi jam lembur (M5), membangun sistem informasi (M11), dan pelatihan penggunaan sistem informasi (M12).

\section{Kesimpulan dan Saran}

Hasil identifikasi dengan metode House of Risk diperoleh 27 risk agent dan 17 risk event pada rantai pasok IKM X. Dari HOR 1 dapat diketahui terdapat 8 risiko prioritas untuk diselesaikan. Risiko tersebut antara lain adalah Tidak ada standar dalam sistem produksi, turnover pekerja tinggi, tidak ada safety stock, pekerja yang sering tidak masuk, tidak ada training untuk pekerja baru, jumlah permintaan konsumen yang tidak pasti, tidak ada area untuk gudang barang jadi, tidak menggunakan sistem informasi. Sedangkan dari hasil HOR 2 diperoleh 13 tindakan mitigasi berdasarkan penilaian dari pihak IKM dengan prioritas mitigasi yaitu membuat SOP sistem produksi, membuat pelatihan untuk pekerja baru, dan membuat panduan standar perekrutan pekerja baru sehingga diharapkan dapat menurunkan turnover pekerja.

\section{Daftar Pustaka}

[1] Anggrahini, D., Karningsih, P. D. and Sulistiyono, M. "Managing Quality Risk in a Frozen Shrimp Supply Chain: A Case Study", Procedia Manufacturing, vol.4, pp. 252-260, 2015. doi: 10.1016/j.promfg.2015.11.039. 2015 
[2] Dewi, D. S., Syairudin, B. and Nikmah, E. N. "Risk Management in New Product Development Process for Fashion Industry: Case Study in Hijab Industry", Procedia Manufacturing, vol. 4, pp. 383391, 2015., doi: 10.1016/j.promfg.2015.11.054.

[3] Geraldin, L. H., Pujawan, I. N., and Dewi, D. S. "Manajemen Risiko dan Aksi Mitigasi untuk Menciptakan Rantai Pasok yang Robust", Jurnal Rekayasa Teknik Sipil TORSI, pp.53-64, Mar. 2007.

[4] Hadiguna, R. A. "Model Penilaian Risiko Berbasis Kinerja untuk Rantai Pasok Kelapa Sawit Berkelanjutan di Indonesia", Jurnal Teknik Industri, vol. 14, no. 1, pp. 13-24, Jun. 2012. doi: 10.9744/jti.14.1.13-24.

[5] Harland, C., Brenchley, R. and Walker, H. "Risk in supply networks", Journal of Purchasing and Supply Management, vol. 9, pp. 51-56, 2003. doi: 10.1016/S14784092(03)00004-9.

[6] Kristanto, B. R. and Hariastuti, N. L. P. "Aplikasi Model House of Risk ( HOR) untuk Mitigasi Risiko pada Supply Chain Bahan Baku Kulit”, Jurnal Ilmiah Teknik Industri, vol. 13, no. 2, pp. 149-157, 2014.
[7] Pujawan, I. N and Mahendrawathi., Supply Chain Management, 3rd ed. Yogyakarta: ANDI, 2017.

[8] Rangel, D. A., De Oliveira, T. K. and Leite, M. S. A. "Supply chain risk classification: Discussion and proposal", International Journal of Production Research, vol. 53, pp. 6868-6887, 2015.2 doi: 10.1080/00207543.2014.910620.

[9] Sholichah, W. et al. "Analisis Risiko Makanan Halal di Restoran Menggunakan Metode Failure Mode and Effect Analysis", Jurnal Ilmiah Teknik Industri, vol. 16, no.2, pp. 150-156, 2017. doi: 10.23917/jiti.v16i2.4941.

[10] Suharjito, S. et al. "Identifikasi dan Evaluasi Risiko Manajemen Rantai Pasok Komoditas Jagung dengan Pendekatan Logika Fuzzy", Jurnal Manajemen dan Organisasi, vol. 1, no. 2, pp. 118-134 , 2010. doi: 10.29244/jmo.v1i2.14157.

[11] Waters, D. Supply Chain Risk Management: Vulnerability and Resilience in Logistics, 2nd ed., Kogan Page Limited, 2011. 